\title{
High frequency chest wall oscillation in cystic fibrosis
}

\section{Judy M Bradley}

Airway clearance is considered an integral component of the management of cystic fibrosis (CF). Recent CF pulmonary guidelines made recommendations using the US Prentative Service task Force (USPSTF) grading scheme (a system which provides a mechanism to weigh the quality of evidence and the potential harms and benefits) on airway clearance. ${ }^{12}$ These guidelines recommended that airway clearance should be provided to all patients with CF (grade B recommendation: high certainty that the net benefit is moderate and at least moderate certainty that the net benefit is moderate to substantial). ${ }^{1}$ They also summarise the evidence for the efficacy of one airway clearance regime versus another and recommend (grade B) that no airway clearance regime has been shown to be superior to others although they recognise that, for any individual, one airway clearance regime may be superior. They advocate that patients should be able to choose, in collaboration with the therapist, which airway clearance regime/ regimes they wish to use. Other guidelines and systematic reviews as well as many primary trials agree that there is no clear advantage of one particular airway clearance regime over another. ${ }^{3}$

The active cycle of breathing techniques (ACBT) is the standard airway clearance regime in the UK, although in the last few years other forms of airway clearance (eg, autogenic drainage) as well as a range of adjuncts have become popular (eg, positive expiratory pressure (PEP) mask, flutter and Acapella). These adjuncts are often provided "free" at the point of delivery to the patient within the current healthcare system. In the USA, high frequency chest wall oscillation (HFCWO; known as the Vest) is widely used and is purchased for patients under various insurance schemes. HFCWO is not widely provided to patients with CF in the UK or the Republic of Ireland, and patients who currently use it have often purchased it themselves. The UK and the Republic of Ireland have experienced a huge move by patients to have access to HFCWO. At present, patient choice to use HFCWO is set against its significant cost (around $£ 8000$ per Vest),

Correspondence to Dr J M Bradley, Physiotherapy, Health and Rehabilitation Sciences Research Institute, University of Ulster, UK; jm.bradley@ulster.ac.uk and there is a lack of sound evidence on its superiority or on equivalence to other much less expensive treatments that are currently part of standard treatment for CF.

The CF pulmonary guidelines have summarised the evidence available for HFCWO compared with other forms of airway clearance. Studies $(n=10)$ comparing HFCWO with other forms of airway clearance were mostly limited to very short studies comparing one session or a number of days of treatment. Some of the studies have compared HFCWO with conventional chest physiotherapy (postural drainage and percussion). In general, these studies showed no difference in lung function or sputum production ${ }^{4-6}$ or favoured HFCWO. ${ }^{7-9}$ Conventional chest physical therapy (CCPT) can be associated with some side effects. When CCPT is performed in a head-down position, it can aggravate gastro-oesophageal reflux and induce adverse reactions, including bronchospasm, changes in cardiac rhythm and increased intracranial pressure. ${ }^{10-12}$ Moreover, patients find CCPT so burdensome that adherence with the prescribed treatment regime is probably less than $50 \%{ }^{13}$ Even hospitalised adolescents in a controlled setting showed significant (35\%) nonadherence to a CCPT regime. ${ }^{14}$ Postural drainage and percussion is not considered standard airway clearance in the UK, and therefore the results-whether positive or not-have limited applicability in the UK.

Some studies (also short-term) have compared HFCWO with treatments recognised as standard airway clearance in the UK. Compared with PEP, there was no difference in either lung function or sputum production. ${ }^{15}$ When compared with oscillating PEP, one study showed a benefit in terms of sputum production and found no difference in lung function. ${ }^{5} 16$ When HFCWO was compared with ACBT, ACBT was better in terms of sputum production and lung function. ${ }^{17}$

The lack of published evidence comparing HFCWO with airway clearance techniques frequently used in the UK and Europe provided the main justification for the randomised crossover study by Osman and colleagues in this issue of Thorax (see page 196). ${ }^{18}$ The study compares the efficacy of 2 days of HFCWO with 2 days of usual airway clearance in 29 patients with
CF. The crossover design used in this study (chosen presumably to improve the efficiency of the study and also to facilitate patient comparison between treatments) assumes that the treatment on one day did not "carry over" and alter the response to the treatment on the next day, and an analysis is presented which suggests that this was the case. The authors optimised their design by ensuring that patients were familiarised with both interventions, HFCWO was optimally delivered using recommended instructions for use, and the length of each treatment session was standardised. The primary outcome measures were carried out by an independent assessor and included wet weight of sputum (collected during the treatment session and also during each $24 \mathrm{~h}$ session), forced expiratory volume in $1 \mathrm{~s}$, pulsed arterial oxygen saturation, urinary leakage and patient-reported preference. The study showed that patients cleared more sputum (during a treatment session and over $24 \mathrm{~h}$ ) using usual airway clearance than with HFCWO. Patients perceived usual treatments to be more effective, and this was not affected by order or day of treatment. The authors conclude that, considering the cost of HFCWO compared with other airway clearance techniques and the differing healthcare systems in the USA and the UK, it is unlikely that HFCWO will be the first choice of airway clearance in the UK.

It is indeed unlikely that HFCWO could be offered within current funding arrangements in the UK National Health Service unless future research or the results of currently active trials such as the 1-year Canadian trial comparing HFCWO with their standard treatment-PEP (http://ClinicalTrials.gov identifier NCT00817180) show significant benefits of HFCWO that outweigh the considerable cost. Further research with HFCWO remains important, as we have an obligation to provide our patients with scientific evidence to justify our current practice. Osman and colleagues have provided preliminary data which could be used to design a long-term study comparing the efficacy of HFCWO with usual airway clearance in the UK. Such a study would be complex, multicentre and expensive, and yet unlikely to attract the same funding as other types of trials such as new drug therapies. Airway clearance is rated as one of the most troublesome parts of treatment in CF and so-perhaps in response to patient demands-patient organisations should seek to lobby funding bodies to prioritise and/or commission research on HFCWO. Collaboration between teams of researchers and clinicians will be essential to design and 
deliver a definitive trial examining the efficacy of HFCWO.

There is unlikely ever to be a perfect airway clearance regime. Decisions regarding the optimal airway clearance regime for patients are not easy, and are complicated by the various clinical phenotypes of patients with CF and the number of options available. It is probable that all airway clearance regimes work by different mechanisms to enhance airflow and reduce mucus viscosity, both of which are important for optimal airway clearance. ${ }^{19}$ Before new devices become available, research needs to provide clear evidence that the new device can achieve enhanced airway flow and changes in viscosity required for optimal airway clearance. Research also needs to focus on the role of devices in specific subgroups of patients (eg, patients with large sputum volumes or non-productive of sputum) or in specific situations (eg, in stable disease or during an exacerbation). There is a high demand on patients with CF to take part in both pharmaceutical and non-pharmaceutical studies so, in order for these physiotherapy trials to be prioritised in terms of funding and patient recruitment, the physiotherapy community needs consensus on what is the best study design to provide these sources of evidence, what sample sizes are required, how long these studies need to be and which outcome measures are appropriate. Lung function has been traditionally accepted as the primary outcome in airway clearance trials. However, the rate of change in lung function is slowing so much and is now as low as $1 \%$, so it is unlikely that future airway clearance trials will be able to show any clear benefit in terms of lung function. This has been highlighted in a recent European Cystic Fibrosis Society (ECFS) consensus conference report on clinical trials which stated that new alternative outcomes need to be used. ${ }^{20}$ Physiological measures such as lung clearance index, cough monitors and sputum viscosity show promise as outcome measures, although consensus is needed on standardising the methodologies for these outcomes. Data are also needed on what magnitude of change is needed in these outcomes to translate into an important change in a clinical outcome. More emphasis needs to be put on how best to capture patients' experiences of different treatments in trials (both positive and negative), and data on adherence will be particularly important.

In conclusion, appropriately designed trials of adequate size using new alternative outcomes will ensure that future airway clearance trials provide us with the information we need to make informed decisions on the options for effective airways clearance techniques.

\section{Competing interests None.}

Provenance and peer review Commissioned; not externally peer reviewed.

Thorax 2010;65:189-190.

doi:10.1136/thx.2009.122663

\section{REFERENCES}

1. Flume PA, Robinson KA, O'Sullivan BP, et al. Cystic fibrosis pulmonary guidelines: airway clearance therapies. Respir Care 2009;54:522-37.

2. Harris RP, Helfand M, Woolf SH, et al. Current methods of the US Preventive Services Task Force: a review of the process. Am J Prev Med 2001;20Suppl 3):P21-35.

3. Clinical guidelines for the physiotherapy management of cystic fibrosis. January 2002

4. Bauer ML, McDougal J, Schoumacher RA. Comparison of manual and mechanical chest percussion in hospitalized patients with cystic fibrosis. J Pediatr 1994:124:250-4.

5. Varekojis SM, Douce FH, Flucke RL, et al. A comparison of the therapeutic effectiveness of and preference for postural drainage and percussion, intrapulmonary percussive ventilation, and high-frequency chest wall compression in hospitalized cystic fibrosis patients. Respir Care 2003:48:24-8

6. Cantin AM, Bacon M, Berthiaume Y. Mechanical airway clearance using the frequencer electro- acoustical transducer in cystic fibrosis. Clin Invest Med 2006:29:159-65.

7. Kraig R, Kirkpatrick KR, Howard D, et al. A direct comparison of manual chest percussion with acoustic percussion, an experimental treatment for cystic fibrosis [abstract]. Am J Respir Crit Care Med 1995;151:P738.

8. Kluft J, Beker $\mathrm{L}$, Castagnino $\mathrm{M}$, et al. A comparison of bronchial drainage treatments in cystic fibrosis. Pediatr Pulmonol 1996;22:271-4.

9. Warwick WJ, Wielinski CL, Hansen LG. Comparison of expectorated sputum after manual chest physical therapy and high-frequency chest compression. Biomed Instrum Technol 2004;38:470-5.

10. Button BM, Heine RG, Catto-Smith AG, et al. Postural drainage and gastro-oesophageal reflux in infants with cystic fibrosis. Arch Dis Child 1997;76:148-50.

11. Campbell AH, O'Connell JM, Wilson M. The effect of chest physiotherapy upon the FEV1 in chronic bronchitis. Med J Aust 1975;1:33-5.

12. Naylor JM, Chow CM, McLean AS. Cardiovascular responses to short term head-down positioning in healthy young and older adults. Physiother Res Int 2005; 10:32-47

13. Lapin C. Conventional postural drainage and percussion: is this still the gold standard? Pediatr Pulmonol 1994:10:P87-8.

14. Czajkowski DR, Koocher GP. Predicting medical compliance among adolescents with cystic fibrosis. Health Psych 1986;5:297-305.

15. Darbee JC, Kanga JF, Ohtake PJ. Physiologic evidence for high-frequency chest wall oscillation and positive expiratory pressure breathing in hospitalized subjects with cystic fibrosis. Phys Ther 2005:85:1278-89.

16. Oermann CM, Sockrider MM, Giles D, et al. Comparison of high-frequency chest wall oscillation and oscillating positive expiratory pressure in the home management of cystic fibrosis: a pilot study. Pediatr Pulmonol 2001:32:372-7.

17. Phillips GE, Pike SE, Jaffe A, et al. Comparison of active cycle of breathing and high-frequency oscillation jacket in children with cystic fibrosis Pediatr Pulmonol 2004:37:71-5.

18. Osman LP, Roughton M, Hodson ME, et al. Shortterm comparative study of high frequency chest wall oscillation and European airway clearance techniques in patients with cystic fibrosis. Thorax 2010;65:196-200.

19. Pryor JA, Main E, Agent P, et al. Physiotherapy. In: Bush A, Alton EWFW, Davies JC, et al, eds. Cystic fibrosis in the 21st century. Basel, Switzerland: Progress in Respiratory Research 2006:24:301-8.

20. Döring G, Elborn JS, Johannesson $\mathrm{M}$, et al. for the Consensus Study Group. Clinical trials in cystic fibrosis. J Cyst Fibros 2007;6:85-99.

\section{Novel pulmonary biomarkers in the diagnosis of VAP}

\section{Paul Johnston, ${ }^{1}$ Danny F McAuley, ${ }^{1,2}$ Cecilia M O'Kane ${ }^{2}$}

${ }^{1}$ Regional Intensive Care Unit, Royal Victoria Hospital, Belfast Health and Social Care Trust, Belfast, UK; ${ }^{2}$ Centre for Infection and Immunity, Queen's University Belfast, UK

Correspondence to Dr Cecilia M O'Kane, Centre for Infection and Immunity, Queen's University Belfast, Lisburn Road, Belfast BT9, UK
Ventilator-associated pneumonia (VAP) is reported to occur in up to $20-27 \%$ of mechanically ventilated patients, and impacts healthcare in terms of patient morbidity, mortality and expenditure. ${ }^{1-3}$ The concept of VAP seems straightfor- ward-that is, alveolar inflammation due to an infectious agent that was not present at the time of initiation of mechanical ventilation. However, the diagnosis remains difficult. Importantly, this difficulty in diagnosis of VAP leads to potential over-/underprescription of antibiotics and misguided treatment.

The American Thoracic Society guidelines of $2005^{3}$ suggest that the use of readily available clinical data is adequate to inform the diagnosis of VAP. However, while such an approach has the advantage of being straightforward to apply, when compared with postmortem histological specimens the resultant sensitivity and 